\title{
Computer Use, Job Tasks and the Part-Time Pay Penalty
}

Citation for published version (APA):

Elsayed, A., de Grip, A., \& Fouarge, D. (2017). Computer Use, Job Tasks and the Part-Time Pay Penalty. British Journal of Industrial Relations, 55(1), 58-82. https://doi.org/10.1111/bjir.12175

Document status and date:

Published: 01/03/2017

DOI:

10.1111/bjir.12175

Document Version:

Publisher's PDF, also known as Version of record

Document license:

Taverne

Please check the document version of this publication:

- A submitted manuscript is the version of the article upon submission and before peer-review. There can be important differences between the submitted version and the official published version of record.

People interested in the research are advised to contact the author for the final version of the publication, or visit the DOI to the publisher's website.

- The final author version and the galley proof are versions of the publication after peer review.

- The final published version features the final layout of the paper including the volume, issue and page numbers.

Link to publication

\footnotetext{
General rights rights.

- You may freely distribute the URL identifying the publication in the public portal. please follow below link for the End User Agreement:

www.umlib.nl/taverne-license

Take down policy

If you believe that this document breaches copyright please contact us at:

repository@maastrichtuniversity.nl

providing details and we will investigate your claim.
}

Copyright and moral rights for the publications made accessible in the public portal are retained by the authors and/or other copyright owners and it is a condition of accessing publications that users recognise and abide by the legal requirements associated with these

- Users may download and print one copy of any publication from the public portal for the purpose of private study or research.

- You may not further distribute the material or use it for any profit-making activity or commercial gain

If the publication is distributed under the terms of Article $25 \mathrm{fa}$ of the Dutch Copyright Act, indicated by the "Taverne" license above, 


\title{
Computer Use, Job Tasks and the Part-Time Pay Penalty
}

\author{
Ahmed Elsayed, Andries de Grip and Didier Fouarge
}

\begin{abstract}
Using data from the UK Skills Surveys 1997-2012, we show that the part-time pay penalty (PTPP) for women within low-and medium-skilled occupations has decreased significantly. The convergence in computer use and non-routine job tasks between part-time and full-time workers explains a large share of the decrease in the PTPP. This convergence took place mainly within occupations, and was not driven by changes in occupational segregation between the two groups of workers. The lower PTPP is also related to changes in the returns to job tasks. Relative changes in the importance of and returns to computer use and job tasks together explain more than 50 per cent of the decrease in the PTPP.
\end{abstract}

\section{Introduction}

In several OECD countries, a large share of the female labour force is employed on a part-time basis. In the United Kingdom, for example, about 40 per cent of the female labour force works part-time (Connolly and Gregory 2010). The employment of these part-time workers is characterized by lower levels of general and specific skills, restricted opportunities for improvement and poor career prospects (Gallie and Zhou 2011). In addition, they usually earn lower hourly wages than full-time workers (Connolly and Gregory 2009; Manning and Petrongolo 2008). Manning and Petrongolo (2008) investigated the part-time pay penalty (PTPP) among female workers in the United Kingdom and showed that a large share of the PTPP is attributed to occupational segregation between part-time and full-time workers where parttime workers sort into relatively low-skilled occupations that pay low hourly wages. However, recent years witnessed relative improvements in educational level as well as training participation of part-time workers compared to fulltime workers in Britain (Gallie and Zhou 2011). Such skills' improvements 
should be accompanied by higher wages for part-time workers. In addition, the widespread computer use in the workplace, driven by declining prices of information technology (Autor et al. 2003), is expected to have affected parttime workers more than full-time workers in more recent years, given their initial lower level of computer use. This could have changed the job content of part-time workers, relative to full-time workers, into more input of nonroutine tasks that are complementary to computer use (Autor et al. 2003), which might have increased the relative pay of part-time workers. However, the extent to which the pay of part-time workers has improved compared to full-time workers, and the extent to which relative changes in computer use and job tasks could explain this improvement in part-time pay, have not been investigated in the literature.

In this article, we use data on employed women from the UK Skills Surveys which contain detailed data on wages, computer use and tasks performed by workers in their jobs over the period 1997-2012, to document the decrease in the PTPP in this period and to investigate the source of this decrease. A decrease in the PTPP could be attributed to two factors. Firstly, it could be attributed to changes in the occupational structure between part-time and full-time workers as part-time workers, because of their rising skills level, now more often sort into higher skilled occupations that pay higher wages compared to what they did in the past (i.e. changes in occupational segregation hypothesis). Secondly, a decrease in the PTPP could be attributed to the increased use of computer technology that contributed to a convergence in the non-routine tasks input between part-time workers and full-time workers and thereby enhanced the relative productivity of part-time workers within occupations (i.e. changes in relative productivity hypothesis). We examine the extent to which shifts in computer use and job tasks could explain changes in the PTPP, and investigate whether these shifts take place across or within occupations. We limit the analysis to workers in low- and mediumskilled occupations because part-time workers hardly sort into high-skilled occupations (Manning and Petrongolo 2008), and because part-timers who sort in high-skilled occupations have human capital characteristics close to those of full-time workers and usually work as highly specialized agency workers who get remunerated at a higher hourly rate than regular workers (Manning and Petrongolo 2008). ${ }^{1}$

Our empirical analyses show that there has been a significant decrease in the PTPP over the period 1997-2012. This decrease of the PTPP has been accompanied by convergence in computer use, influencing tasks (i.e. managerial tasks) and maths tasks between part-time and full-time workers. ${ }^{2}$ The convergence in wages and job tasks has taken place mainly within occupations and was not due to changes in the pattern of occupational segregation between part-time and full-time workers. Particularly, the convergence in computer use explains a substantial part of the decrease in the PTPP. Moreover, the change in the PTPP is also affected by changes in wage returns to (i.e. price of) job tasks performed more intensively by full-time workers. While the decreasing wage returns to reading and writing 
have contributed to a decrease in the PTPP, the increasing wage returns to influencing tasks have increased the PTPP despite the convergence in the importance of (i.e. quantity of) influencing tasks between part-time and fulltime workers. We find that relative changes in the importance of and wage returns to computer use and job tasks explain together more than 50 per cent of the wage convergence between part-time and full-time workers in low- and medium-skilled occupations.

The remainder of the article is structured as follows. The next section discusses the related literature. Section 3 describes the data and the variables used in this study. Section 4 explains the empirical strategy and the decomposition techniques used in the analysis. Section 5 reports the results of the data analysis. Finally, Section 6 summarizes the findings and concludes.

\section{Related literature}

In this article we build on the growing literature that emphasizes the relevance of changes in job tasks as well as the literature on the PTPP. Among others, Acemoglou (1998), Autor et al. (2003), Garicano and Rossi-Hansberg (2006), Spitz-Oener (2006) and Snower and Goerlich (2013) have used a task-based framework to study the impact of technological and organizational changes on skill demands and wage inequality. The task-based approach has the advantage of providing direct measures of job tasks at the individual level. It can, therefore, be used to give a comprehensive characterization of changes in job content both across and within occupations, and to investigate the implication of these changes for earning gaps among different groups (Black and Spitz-Oener 2010).

Various studies used this task-based approach to investigate gender differences in job tasks and changes in gender wage inequality (e.g. Black and Spitz-Oener 2010; Lindley 2012). Black and Spitz-Oener (2010) used a task-based framework to investigate changes in the job content of women in Germany. They showed that during the 1970s and the 1980s there was a concentration of women in occupations characterized by intensive routine tasks, and subsequently women experienced larger reductions in routine tasks than men. This led to greater job polarization for women. Lindley (2012) studied gender difference in the changes in skill demands in the United Kingdom and showed that women lost out from technical change between 1997 and 2006 due to their lower maths and literacy skills, as well as other skills required to undertake the tasks that are affected by technical change, particularly in highly computerized industries such as finance and manufacturing. However, these studies were all limited to full-time workers and ignored that in several advanced countries a large share of the female labour force works on a part-time basis (Booth and van Ours 2013; Connolly and Gregory 2010; Iseke 2014).

The literature investigated pay differences between part-time and full-time workers and showed that being employed part-time results in a pay penalty 
(e.g. Connolly and Gregory 2009; Hirsch 2005; Manning and Petrongolo 2008; Mumford and Smith 2009). Manning and Petrongolo (2008) showed that occupational segregation explains the PTPP to a large extent although not fully. There are, however, hardly any PTPP studies which go more specifically into differences in job content between part-time and full-time workers. One exception is the study by Hirsch (2005) which showed that the wage gap between part-time and full-time workers in the US could, to a large extent, be attributed to differences in job tasks between the two groups. Using the O*NET data which provides detailed descriptions of occupations, Hirsch (2005) showed that part-time workers have generally less verbal, mathematical and problem solving tasks than full-time workers which could partly explain the PTPP. However, as the O*NET data assign identical values to part-time and full-time workers in the same occupation, he could not disentangle the impact of occupational segregation on the PTPP from that of different job tasks within particular occupations. Moreover, the relative change over time in computer use and job tasks of part-time workers and the associated change in the PTPP have not yet been addressed in the literature.

\section{Data and descriptive statistics}

For our analyses, we use data on female workers aged 20 to 60 years old from the four waves of the UK Skills Surveys 1997, 2001, 2006 and 2012. The UK Skills Surveys are repeated surveys that contain cross-sectional data on employment conditions, general skills, wages, as well as occupation, industry and firm size. More importantly, the surveys contain detailed information on workers' computer use and job tasks. We exclude self-employed workers and use a consistent sample of cases with full information on demographic characteristics, job tasks, human capital, occupation and wage $(N=5589){ }^{3}$ Following Manning and Petrongolo (2008), we use the self-reported part-time status as our measure of part-time employment. ${ }^{4}$ We analyse changes over time in wage, computer use and job tasks of part-time workers relative to fulltime workers. A worker's wage is assessed by the self-reported gross hourly wage. In case it is not directly reported, this variable is calculated from the gross usual weekly pay divided by the weekly hours of work.

Computer use is assessed by a dummy variable that takes the value 1 if the worker uses a computer at work, and 0 otherwise. ${ }^{5}$ Autor et al. (2003) have introduced the distinction between routine and non-routine tasks to study how computerization substitutes for workers in performing routine tasks while it complements workers in performing non-routine tasks. However, the way job tasks are addressed in the UK Skills Surveys makes it difficult to make such a distinction between routine and non-routine tasks (Green 2012). Job tasks in the UK Skills Surveys are measured through a detailed list of questions in which respondents are asked to indicate the importance of every single task in their job on a five-point scale ranging from 'essential', to 'not at all important/does not apply'. We group the 29 job tasks distinguished in the 
four waves of the UK Skills Surveys into seven generic tasks by calculating average scores. The seven generic tasks we refer to are reading and writing, maths, external communication, influencing, self-planning, problem solving and physical tasks. The full list of the underlying job tasks is reported in Table A1. ${ }^{6}$ This division is based on a factor analysis similar to the one used by Dickerson and Green (2004) using the 1997 and 2001 waves of the UK Skills Surveys. To account for possible correlations among the generic tasks, we follow the approach of Dickerson and Green (2004) by employing an oblique rotation (Promax method, with a power of 4), which allows for possible correlations among the tasks. However, the classification is not sensitive to the choice of the rotation method.

Part-time workers are less likely to sort into high-skilled occupations (Manning and Petrongolo 2008). Therefore, we divide the sample into (1) high-skilled occupations and (2) low- and medium-skilled occupations. ${ }^{7}$ The high-skilled occupations include corporate managers and senior officials, science and technology professionals, health professionals, teaching and research professionals and business and public service professionals. All other occupations are referred to as the low- and medium-skilled occupations. Table A2 shows the difference in wage, computer use and job tasks as well as other relevant variables between part-time and full-time workers. The table shows that there is a significant PTPP in the low- and medium-skilled occupations. However, there is a part-time pay premium in the high-skilled occupations. At both occupational-skill levels, full-time workers score significantly higher than part-timers in all tasks, with the exception of physical tasks. However, the difference in job tasks between part-time and full-time workers in the low- and medium-skilled occupations is more pronounced than the difference in the high-skilled occupations. The table also shows that part-time workers are generally older, less educated and less trained than full-time workers. In addition, they are more likely to be married and have children. However, the low number of part-time workers in high-skilled occupations makes it difficult to reach conclusive findings regarding relative changes in wage, computer use and job tasks. Therefore, we limit our further analyses to the low- and mediumskilled occupations.

Figure 1 shows graphically changes in the PTPP and shifts in the differences in computer use and job tasks between part-time and full-time workers in the low- and medium-skilled occupations. The graph shows that the PTPP decreased significantly between 1997 and 2012. ${ }^{8}$ Computer use, problem solving, self-planning, influencing, maths and reading and writing tasks show a clear pattern of convergence between part-time and full-time workers over the same period of time. However, physical and external communication tasks show a pattern of divergence between part-time and full-time workers. ${ }^{9}$

Table A 3 shows the levels of wage, computer use and job tasks for part-time and full-time workers, the differences in the score of these aspects in the lowand medium-skilled occupations for all four waves, as well as changes in these differences over-time. The table shows that full-time workers earn higher wages and have higher levels of computer use and job tasks (with the exception of 
FIGURE 1

Shifts in the differences in pay, computer use and job tasks between full-time and part-time workers.
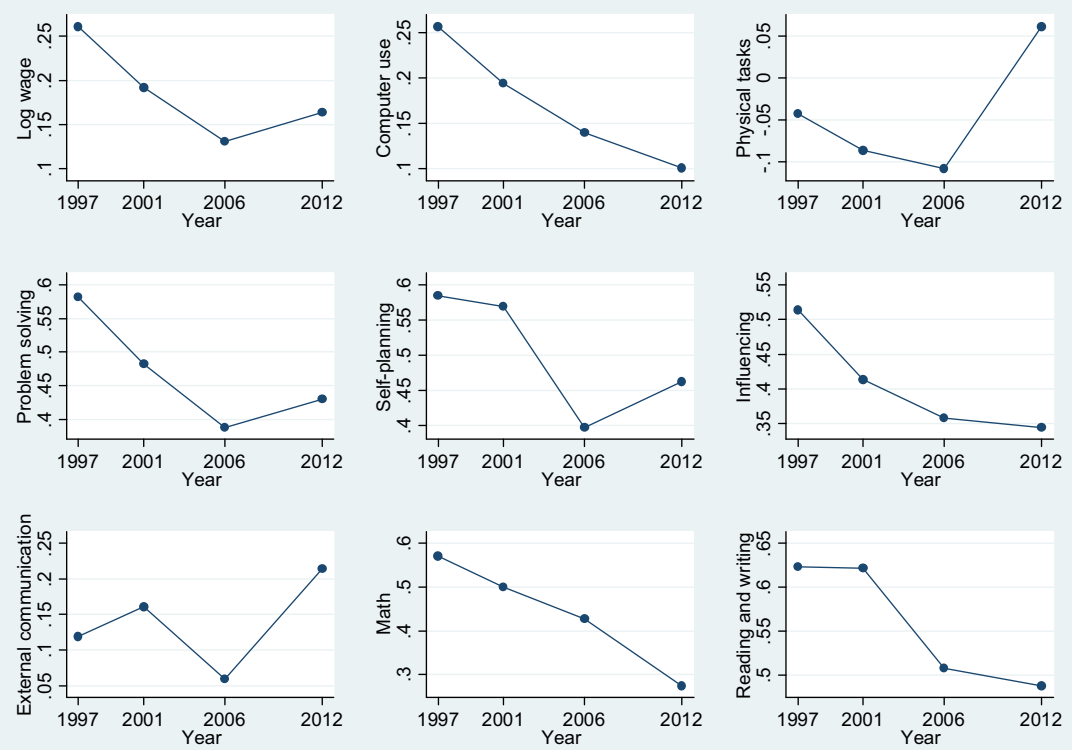

Note: The Y-axis referes to differences in the average of scores between full-time and part-time workers. Therefore, a negative trend shows improvement in the score of part-time relative to full-time workers, while a positive trend shows worsening in the score of part-time relative to full-time workers.

physical tasks) than part-time workers. It also shows a convergence between part-time and full-time workers in wage, computer use and various job tasks, especially problem solving, self-planning, influencing and maths tasks. The table further shows levels of (and changes in) demographic variables and background characteristics between part-time and full-time workers. The share of married part-time workers and the share of part-time workers with no qualifications decreased significantly relative to full-time workers between 1997 and 2012. Moreover, the table shows that the share of part-time workers witnessed a continuous decline over time from 46.1 per cent in 1997 to 43.8 per cent in 2012. This suggests that convergence in computer use and job tasks between part-time and full-time workers is not driven by an increase in the share of part-time workers replacing full-time workers in occupations. ${ }^{10}$

Figure 2 shows the relationships between the PTPP and differences in job tasks between full-time and part-time workers. The figure shows that larger differences in computer use, problem solving, self-planning, influencing, maths and reading and writing between full-time and part-time workers are associated with a higher PTPP. 
FIGURE 2

The relationships between the PTPP and differences in job tasks between full-time and part-time workers.
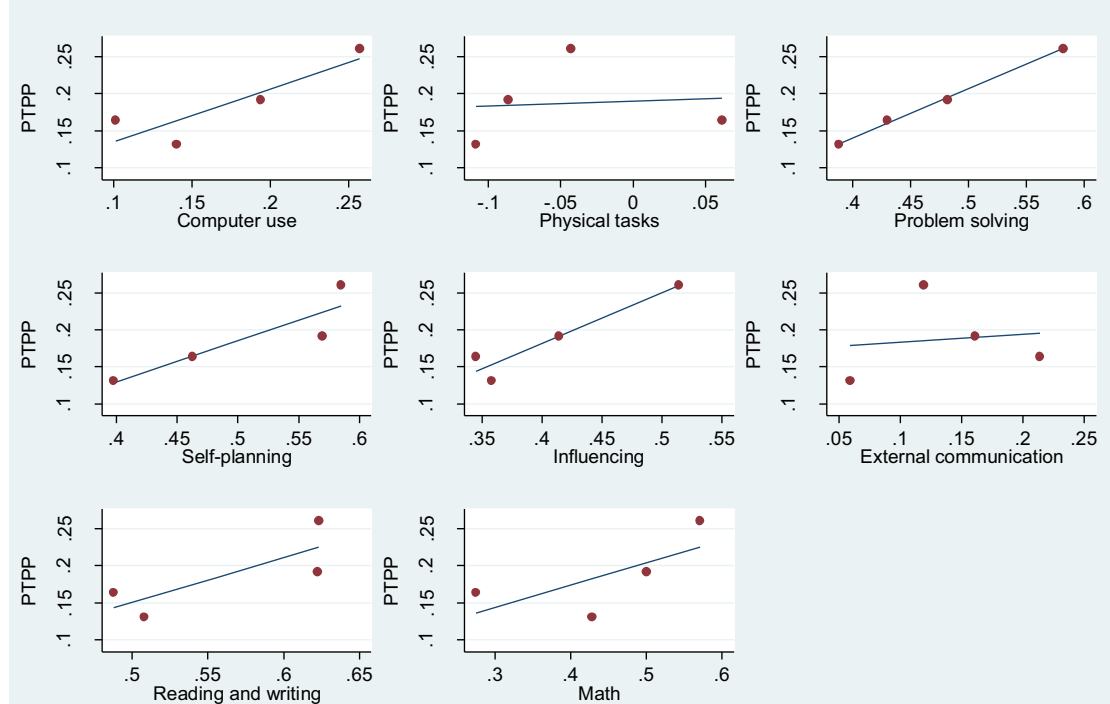

Fitted values

pay

Note: PTPP is the difference in pay between full-time and part-time workers (i.e. Pay FT Pay PT). The X-axis refers to differences in the average score of each task between full-time and part-time workers (i.e. Task FT -Task PT).

\section{Empirical strategy}

\subsection{Changes in the PTPP and job tasks}

To estimate changes in the PTPP and changes in job tasks between part-time and full-time workers over the period 1997-2012, we use the following two equations:

$$
\begin{aligned}
& W_{i}=\alpha+\beta_{1} P T_{i}+\beta_{2} Y_{i}+\beta_{3}\left[P T_{i} * Y_{i}\right]+\beta_{4} X_{i}+\varepsilon_{i} \\
& T_{i}=\varphi+\gamma_{1} P T_{i}+\gamma_{2} Y_{i}+\gamma_{3}\left[P T_{i} * Y_{i}\right]+\gamma_{4} X_{i}+e_{i}
\end{aligned}
$$

where $W_{i}$ is the worker's log wage and $T_{i}$ is the level of a specific task input. $P T$ is a dummy variable that takes the value 1 if the worker is a part-timer and 0 otherwise. $Y_{i}$ is a continuous variable for the time trend that takes into account year differences across the waves of the surveys, so that one point increase in $Y_{i}$ is equivalent to one additional year. ${ }^{11}$ The coefficient of the interaction term between $P T_{i}$ and $Y_{i}$ captures the change in the PTPP in equation (1) and the change in job task levels between part-time and full-time workers in equation 
(2). $X_{i}$ is a set of control variables that includes worker's age, age squared, level of education, training participation, work experience, work experience squared, industry sector, firm size and occupational dummies. $\varepsilon_{i}$ and $e_{i}$. are error terms.

\subsection{Changes within versus across occupations}

Recent literature on the PTPP has shown that occupational segregation explains a large share of the PTPP (e.g. Manning and Petrongolo 2008). As part-time workers sort into relatively low-skilled occupations, which pay lower hourly wages, they earn less than full-timers (Manning and Petrongolo 2008). To investigate to what extent changes in occupational segregation could have explained the decrease in the PTPP, we decompose the relative changes in wages into changes that are due to changes in average wages within occupations (i.e. how much of the difference can be explained by the possibility that part-time and full-time workers experience different wage changes within occupations) and those that are due to occupational shifts in the employment of part-time and full-time workers across occupations. For this purpose, we use the Oaxaca and Ransom (1994) decomposition approach to apportion the change in the mean of wages over time for part-time and full-time workers. The decomposition of the mean shifts in wages between part-time and full-time workers is calculated as:

$$
\begin{aligned}
\left(\bar{W}_{y 2}-\bar{W}_{y 1}\right)_{\mathrm{FT}}-\left(\bar{W}_{y 2}-\bar{W}_{y 1}\right)_{\mathrm{PT}} & \\
= & {\left[\left(J_{y 2}-J_{y 1}\right) \hat{\lambda}^{*}+\left\{J_{y 2}\left(\hat{\lambda}_{y 2}-\hat{\lambda}^{*}\right)+\left(J_{y 1}\right)\left(\hat{\lambda}^{*}-\hat{\lambda}_{y 1}\right)\right\}\right]_{\mathrm{FT}} } \\
& -\left[\left(J_{y 2}-J_{y 1}\right) \hat{\lambda}^{*}+\left\{J_{y 2}\left(\hat{\lambda}_{y 2}-\hat{\lambda}^{*}\right)+\left(J_{y 1}\right)\left(\hat{\lambda}^{*}-\hat{\lambda}_{y 1}\right)\right\}\right]_{\mathrm{PT}}
\end{aligned}
$$

where $\bar{W}_{y}$ PT and $\bar{W}_{y \text { FT }}$ are the average wage in time period $y$ for parttimers and full-timers, respectively. $J_{y 2}$ and $J_{y 1}$ are vectors containing occupational dummies and a constant term for the time periods $y_{2}$ and $y_{1}$, respectively. $\hat{\lambda}_{y 2}$ and $\hat{\lambda}_{y 1}$ are vectors with the slope parameters and the intercept for the time periods $y_{2}$ and $y_{1}$, respectively. $\hat{\lambda}^{*}$ is the non-discriminatory coefficient vector. ${ }^{12}$ The terms $\left[\left(J_{y 2}-J_{y 1}\right) \hat{\lambda}^{*}\right]_{\mathrm{PT}}$ and $\left[\left(J_{y 2}-J_{y 1}\right) \hat{\lambda}^{*}\right]_{\mathrm{FT}}$ represent the part of the change in wages that is explained by occupational changes (i.e. across occupational changes), for part-time and full-time workers, respectively. The terms $\left[J_{y 2}\left(\hat{\lambda}_{y 2}-\hat{\lambda}^{*}\right)+\left(J_{y 1}\right)\left(\hat{\lambda}^{*}-\hat{\lambda}_{y 1}\right)\right]_{\mathrm{PT}}$ and $\left[J_{y 2}\left(\hat{\lambda}_{y 2}-\hat{\lambda}^{*}\right)+\left(J_{y 1}\right)\left(\hat{\lambda}^{*}-\hat{\lambda}_{y 1}\right)\right]_{\mathrm{FT}}$ are the portion of the change in wages that is unexplained by changes in occupations (within occupation changes) for part-time and full-time workers, respectively.

The relative improvement in computer use and job sks for part-time workers can also be broken into two components: (1) changes in the task composition within occupations and (2) changes in the distribution of part-time and full-time workers across occupations. The technological change hypothesis predicts that changes in tasks take place within occupations due to changes in 
the production process (Black and Spitz-Oener 2010). To identify the source of the change in computer use and job tasks, we again use the Oaxaca and Ransom (1994) decomposition approach, replacing log wages in equation (3) by computer use and job tasks.

\subsection{Do changes in computer use and job tasks explain changes in the PTPP?}

To estimate the extent to which convergence in computer use and job tasks between part-time and full-time workers explains the decrease in the PTPP, we use the decomposition approh by Juhn et al. (1991). The advantage of this decomposition technique over any other similar technique (e.g. OaxacaRansom decomposition) is its ability to decompose the explained changes in the PTPP into changes that are due to relative task changes between part-time and full-time workers (changes in quantity), and changes that are due to shifts in the wage returns to tasks (changes in prices). This technique has been widely used in the literature to study changes in gender wage differentials (e.g. Blau and Kahn 1992, 1997; Gupta et al. 2006). The change in the PTPP can initially be written as:

$$
D_{y} \equiv \bar{W}_{y}^{\mathrm{FT}}-\bar{W}_{y}^{\mathrm{PT}}=\left(T_{y}^{\mathrm{FT}}-T_{y}^{\mathrm{PT}}\right) \beta_{y}^{\mathrm{FT}}+\left(\theta_{y}^{\mathrm{FT}}-\theta_{y}^{\mathrm{PT}}\right) \sigma_{y}^{\mathrm{FT}}
$$

where $D_{y}$ is the difference in mean $\log$ wages $\left(\bar{W}_{y}\right)$ in year $y$ between full-time (FT) and part-time (PT) workers. $T_{y}^{\mathrm{FT}}$ and $T_{y}^{\mathrm{PT}}$ are vectors of mean computer use and job tasks in year $y$ for full-time and part-time workers, respectively. $\beta_{y}^{\mathrm{FT}}$ is the OLS parameter estimates of computer use and job tasks at year $y$ for full-time workers. $\sigma_{y}^{\mathrm{FT}}$ is the standard deviations of the residual of the wage equation of full-time workers. $\theta_{y}^{\mathrm{FT}}$ is the standardized residual of the full-time wage regression, with mean 0 and variance $1 .{ }^{13} \theta_{y}^{\mathrm{PT}}=\left(\bar{W}_{y}^{\mathrm{FT}}-T_{y}^{\mathrm{PT}} \beta_{y}^{\mathrm{FT}}\right) / \sigma_{y}^{\mathrm{FT}}$, which reflects the wage a part-time worker would receive if her job tasks are rewarded at the same rate as a full-time worker's tasks are rewarded (deflated by the full-time worker's standardized residuals). Thus, the PTPP at a given point in time comprises an effect due to differences in observed tasks between part-time and full-time workers, weighted by the return received by full-time workers to these tasks, and an effect due to differences in the standardized residual, weighted by residual full-time inequality. Following the notation by Blau and Kahn $(1992,1997)$, the change in the PTPP can be rewritten as:

$$
\begin{aligned}
D_{y 2}-D_{y 1}= & \left(\Delta T_{y 2}-\Delta T_{y 1}\right) \beta_{y 1}^{\mathrm{FT}}+\Delta T_{y 2}\left(\beta_{y 2}^{\mathrm{FT}}-\beta_{y 1}^{\mathrm{FT}}\right) \\
& +\left(\Delta \theta_{y 2}-\Delta \theta_{y 1}\right) \sigma_{y 2}^{\mathrm{FT}}+\Delta \theta_{y 2}\left(\sigma_{y 2}^{\mathrm{FT}}-\sigma_{y 1}^{\mathrm{FT}}\right)
\end{aligned}
$$

where $\Delta$ represents the difference between full-timers and part-timers in the mean of the variable following. The first and second terms of the right-hand side of equation (5) reflect the portion of the change that is explained by changes in computer use and job tasks. The first term is the observed change in quantity of tasks, which reflects changes in the PTPP that are due to observed 
TABLE 1

Change in the PTPP in Low- and Medium-Skilled Occupations, 1997-2012

\begin{tabular}{lcc}
\hline Variables & $(1)$ & $(2)$ \\
& Log wage & Log wage \\
\hline Part-timer & $-0.235^{* * *}$ & $-0.087^{* * *}$ \\
& $(0.026)$ & $(0.023)$ \\
Year & $0.035^{* * *}$ & $0.031^{* * *}$ \\
& $(0.002)$ & $(0.002)$ \\
Part-timer *Year & $0.009^{* * *}$ & $0.007^{* * *}$ \\
& $(0.003)$ & $(0.002)$ \\
Occupational dummies & No & Yes \\
Controls & No & Yes \\
Constant & $1.685^{* * *}$ & $1.724^{* * *}$ \\
& $(0.020)$ & $0.108)$ \\
Observations & 5589 & 5589 \\
$R^{2}$ & 0.096 & 0.232 \\
\hline
\end{tabular}

Notes: OLS estimations, standard errors in parentheses $* * * p<0.01,{ }^{* *} p<0.05,{ }^{*} p<0.1$. Control variables include worker's age, age squared, marital status, number of children, level of education, training participation, work experience, work experience squared, public or private sector, firm size and sector of industry.

changes in part-time/ full-time differences in the inputs of computer use and job tasks. The second term is the observed change in prices, which captures the contribution of changes in the rewards that the labour market attaches to computer use and job tasks of full-time workers. The third and fourth terms of the right-hand side of equation (5) reflect the unexplained part in the Oaxaca and Ransom (1994) decomposition. The change in the unexplained component can be divided in the 'gap effect' (third term) which reflects the changes in the relative position of part-timers in the full-timers residual wage distribution and the 'unobservable prices effect' (fourth term) which measures the change in the wage gap attributed to the change in the distribution of the full-time wage residuals, holding constant the mean part-time ranking in the full-time residual distribution.

\section{Data analyses}

Table 1 shows the coefficient estimates of the change in the PTPP equation (1). Columns 1 and 2 show the estimates without and with the various controls, respectively. The table cleay shows that there has been a significant convergence in wages between part-time and full-time workers in low and medium-skilled occupations over the period 1997-2012. The PTPP decreased yearly by about $0.7 \log$ points over this period. ${ }^{14}$

There could be a selection bias associated with the endogeneity of the decision to work on part-time basis (Manning and Petrongolo 2008). ${ }^{15}$ We have therefore also estimated the model after controlling for selection using standard Heckman sample selection correction techniques. Following Ermisch and Wright (1993) and Manning and Petrongolo (2008) we use the 
number of children and marital status as our exclusion restrictions. The model gives qualitatively similar results to the OLS model (see Table A4).

Table 2 shows the coefficient estimates for the change in computer use and task inputs equation (2). Including all relevant controls, the table clearly shows that part-time workers have lower levels of computer use and job tasks compared to full-time workers. ${ }^{16}$ However, there has been a significant convergence in computer use and influencing between part-time and full-time workers between 1997 and 2012. The same convergence pattern can also be observed, though less clear-cut, for self-planning, reading and writing and maths tasks. ${ }^{17}$

To estimate whether changes in the PTPP, computer use and job tasks took place within or across occupations, Table 3 summarizes the coefficients of the Oaxaca-Ransom decomposition from equation (3) within two-digit occupations between 1997 and 2001 (Panel A), 1997 and 2006 (Panel B) and 1997 and 2012 (Panel C). Columns (1) and (2) show the within-occupation changes for full-time and part-time workers, respectively. Column (3) shows the difference between the changes within occupations between full-time and part-time workers, that is Column (1) minus Column (2). Columns (4) and (5) show the changes in wages, computer use and job tasks that are due to changes in the distribution of employment across occupations for full-time and part-time workers, respectively. Column (6) shows the difference between the change across occupations between full-time and part-time workers, that is (Column 4) minus (Column 5). Column (7) shows the total change in the difference in wages, computer use and tasks of part-time and full-time workers by summing up the relative changes within occupations (Column 3 ) and across occupations (Column 6). ${ }^{18}$

The table shows that the larger part of the decrease in the PTPP took place within occupations. About 59 per cent $[(0.039 / 0.066) \times 100]$ of the change between 1997 and 2001, about 86 per cent $[(0.119 / 0.138) \times 100]$ of the change between 1997 and 2006 and 80 per cent $[(0.092 / 0.115) \times 100]$ of the change between 1997 and 2012 took place within occupations. ${ }^{19}$ This suggests that a great deal of the decrease in the PTPP in low- and medium-skilled occupations was not due to changes in occupational segregation between part-time and full-time workers, but rather due to an improvement in the wages of parttimers compared to those of full-timers within the same occupation. Similarly, the table also shows that the largest changes in computer use and job tasks took place within occupations; particularly for part-time workers. This is consistent with the hypothesis that the productivity gap between part-time and full-time workers has decreased as the task composition of part-time workers gets more similar to that of full-time workers than it was in the past.

To estimate the extent to which relative changes in computer use and job tasks could explain the decrease in the PTPP, Table 4 shows the estimates of the Juhn et al. (1991) decomposition equation (5). ${ }^{20}$ Panel A shows the PTPP estimates for each wave, and Panel B shows the changes in the PTPP across waves. Column 1 shows the overall PTPP. Column 2 shows the portion of the PTPP that is explained by computer use and job tasks. Column 3 shows the 


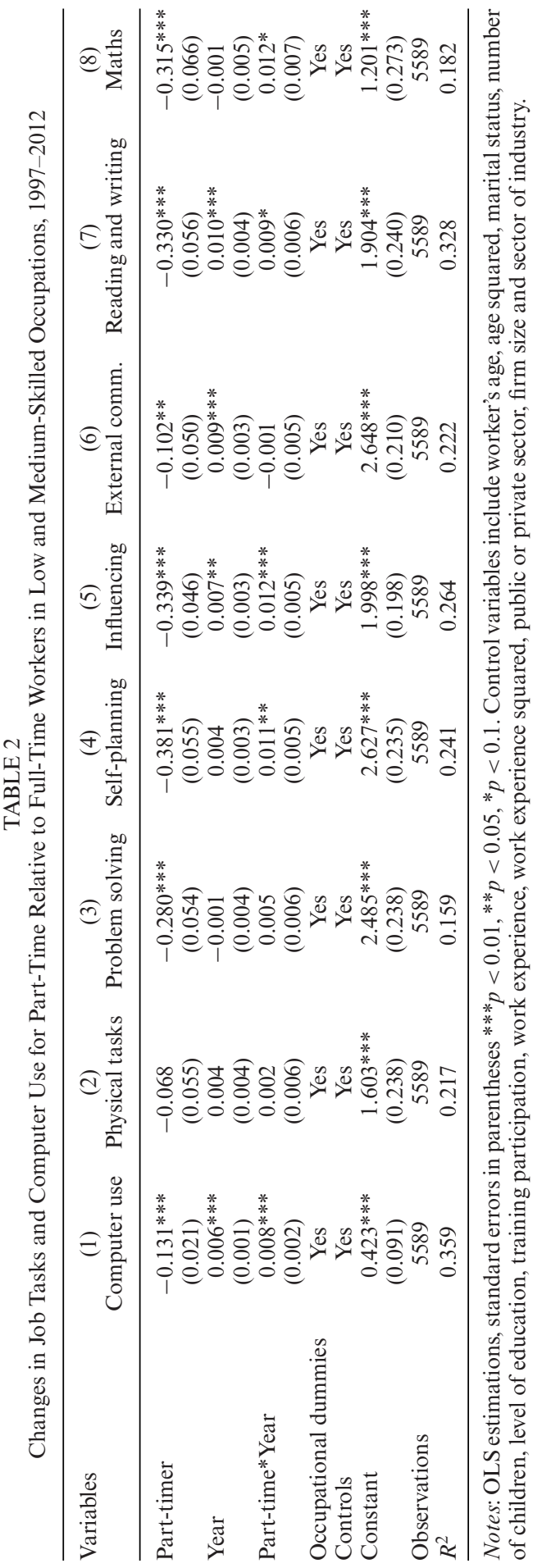


TABLE 3

Oaxaca-Ransom Decomposition of the Change in the PTPP, Computer Use and Job Tasks Over the Period 1997-2012

\begin{tabular}{|c|c|c|c|c|c|c|c|}
\hline & (1) & (2) & (3) & (4) & (5) & (6) & (7) \\
\hline & \multicolumn{3}{|c|}{ Within occupations } & \multicolumn{3}{|c|}{ Across occupations } & Overall change \\
\hline & FT & PT & $\begin{array}{l}\text { FT-PT } \\
(1)-(2)\end{array}$ & FT & PT & $\begin{array}{l}\text { FT-PT } \\
(4)-(5)\end{array}$ & $(3)+(6)$ \\
\hline \multicolumn{8}{|l|}{ (A) 1997-2001 } \\
\hline Pay & 0.125 & 0.164 & -0.039 & 0.032 & 0.059 & -0.027 & -0.066 \\
\hline Computer use & 0.038 & 0.078 & -0.040 & 0.022 & 0.055 & -0.033 & -0.073 \\
\hline Physical & 0.182 & 0.232 & -0.050 & -0.020 & 0.002 & -0.022 & -0.072 \\
\hline Problem solving & 0.011 & 0.070 & -0.059 & 0.034 & 0.092 & -0.058 & -0.117 \\
\hline Self-planning & 0.063 & 0.086 & -0.023 & 0.062 & 0.092 & -0.030 & -0.053 \\
\hline Influencing & 0.008 & 0.097 & -0.089 & 0.081 & 0.100 & -0.019 & -0.108 \\
\hline $\begin{array}{l}\text { External } \\
\text { communication }\end{array}$ & 0.025 & 0.033 & -0.008 & 0.060 & 0.050 & 0.010 & 0.002 \\
\hline Literacy & 0.038 & -0.014 & 0.052 & 0.074 & 0.157 & -0.083 & -0.031 \\
\hline Maths & -0.092 & 0.003 & -0.095 & 0.083 & 0.084 & -0.001 & -0.096 \\
\hline \multicolumn{8}{|l|}{ (B) 1997-2006 } \\
\hline Pay & 0.286 & 0.405 & -0.119 & 0.028 & 0.047 & -0.019 & -0.138 \\
\hline Computer use & 0.059 & 0.165 & -0.106 & 0.009 & 0.030 & -0.021 & -0.127 \\
\hline Physical & 0.129 & 0.215 & -0.086 & 0.044 & 0.009 & 0.035 & -0.051 \\
\hline Problem solving & 0.003 & 0.117 & -0.114 & 0.052 & 0.108 & -0.056 & -0.170 \\
\hline Self-planning & 0.118 & 0.249 & -0.131 & 0.062 & 0.115 & -0.053 & -0.184 \\
\hline Influencing & 0.081 & 0.231 & -0.150 & 0.118 & 0.117 & 0.001 & -0.149 \\
\hline $\begin{array}{l}\text { External } \\
\text { communication }\end{array}$ & 0.057 & 0.196 & -0.139 & 0.075 & 0.017 & 0.058 & -0.081 \\
\hline Literacy & 0.125 & 0.150 & -0.025 & 0.073 & 0.149 & -0.076 & -0.101 \\
\hline Maths & -0.005 & 0.091 & -0.096 & 0.047 & 0.062 & -0.015 & -0.111 \\
\hline \multicolumn{8}{|l|}{ (C) 1997-2012 } \\
\hline Pay & 0.500 & 0.592 & -0.092 & 0.040 & 0.063 & -0.023 & -0.115 \\
\hline Computer use & 0.108 & 0.230 & -0.122 & -0.004 & 0.042 & -0.046 & -0.168 \\
\hline Physical & 0.099 & 0.094 & 0.005 & 0.097 & 0.038 & 0.059 & 0.064 \\
\hline Problem solving & -0.005 & 0.054 & -0.059 & 0.064 & 0.136 & -0.072 & -0.131 \\
\hline Self-planning & 0.135 & 0.247 & -0.112 & 0.088 & 0.142 & -0.054 & -0.166 \\
\hline Influencing & 0.133 & 0.309 & -0.176 & 0.165 & 0.172 & -0.007 & -0.183 \\
\hline $\begin{array}{l}\text { External } \\
\text { communication }\end{array}$ & 0.138 & 0.104 & 0.034 & 0.119 & 0.069 & 0.050 & 0.084 \\
\hline Literacy & 0.182 & 0.299 & -0.117 & 0.123 & 0.204 & -0.081 & -0.198 \\
\hline Maths & -0.060 & 0.206 & -0.266 & 0.049 & 0.080 & -0.031 & -0.297 \\
\hline
\end{tabular}

Note: A negative sign means a decrease in the PTPP. In terms of equation (3): (1) $=\left[J_{y 2}\left(\hat{\lambda}_{y 2}-\right.\right.$ $\left.\left.\hat{\lambda}^{*}\right)+\left(J_{y 1}\right)\left(\hat{\lambda}^{*}-\hat{\lambda}_{y 1}\right)\right]_{\mathrm{FT}},(2)=\left[J_{y 2}\left(\hat{\lambda}_{y 1}-\hat{\lambda}^{*}\right)+\left(J_{y 1}\right)\left(\hat{\lambda}^{*}-\hat{\lambda}_{y 1}\right)\right]_{\mathrm{PT}},(3)=(1)-(2),(4)=\left[\left(J_{y 2}-\right.\right.$ $\left.\left.J_{y 1}\right) \hat{\lambda}^{*}\right]_{\mathrm{FT}},(5)=\left[\left(J_{y 2}-J_{y 1}\right) \hat{\lambda}^{*}\right]_{\mathrm{PT}},(6)=(4)-(5)$ and $(7)=(3)+(6)$.

unexplained portion of the PTPP. Column 4 shows the share of the PTPP that is explained by computer use and job tasks by dividing the explained portion (Column 2) by the raw differential (Column 1). The table shows that the PTPP decreased by $6.7 \log$ points from $25.9 \log$ points in 1997 to $19.2 \mathrm{log}$ points in 2001. It further decreased to $12.1 \mathrm{log}$ points in 2006 , and slightly recovered to $14.3 \mathrm{log}$ points in 2012. The table further shows that a substantial portion of the decrease in the PTPP can be attributed to relative changes in computer use and job tasks: 50 per cent of changes in the PTPP between 1997 and 2006 
TABLE 4

Juhn-Murphy Decomposition of the PTPP Using Computer Use and Job Tasks

\begin{tabular}{lcccc}
\hline & $\begin{array}{c}(1) \\
\text { Raw } \\
\text { differential }\end{array}$ & $\begin{array}{c}(2) \\
\text { Explained } \\
\text { effect }\end{array}$ & $\begin{array}{c}(3) \\
\text { Residual } \\
\text { gap }\end{array}$ & $\begin{array}{c}(4) \\
\text { Share of } \\
\text { explained effect }\end{array}$ \\
\hline $\begin{array}{l}\text { (A) Levels of the PTPP } \\
\text { PTPP 1997 }\end{array}$ & 0.259 & 0.162 & 0.096 & $63 \%$ \\
PTPP 2001 & 0.192 & 0.103 & 0.089 & $54 \%$ \\
PTPP 2006 & 0.121 & 0.093 & 0.028 & $77 \%$ \\
PTPP 2012 & 0.143 & 0.101 & 0.042 & $71 \%$ \\
(B) Changes in the PTPP & & & & \\
PTPP 2001-PTPP 1997 & -0.067 & -0.059 & -0.007 & $88 \%$ \\
PTPP 2006-PTPP 1997 & -0.138 & -0.069 & -0.068 & $50 \%$ \\
PTPP 2012-PTPP 1997 & -0.116 & -0.061 & -0.054 & $53 \%$ \\
\hline
\end{tabular}

Note: Estimates are obtained from regressions of log wages on computer use and job tasks. The change in the PTPP is calculated as $\left(W^{\mathrm{FT}}-W^{\mathrm{PT}}\right)_{y 2}-\left(W^{\mathrm{FT}}-W^{\mathrm{PT}}\right)_{y 1}$. Therefore, a positive sign indicates an increase in the PTPP, and a negative sign indicates a decrease in the PTPP.

(and 53 per cent of the changes between 1997 and 2012) was due to changes in computer use and job tasks between the two groups.

The portion of the PTPP that is explained by relative changes in computer use and job tasks could be divided into a quantity effect where the importance of computer use and job tasks for part-time workers increased relative to full-time workers, and a wage (price) effect that is due to changes in the wage returns to computer use and job tasks. To disentangle the importance (quantity) and the wage (price) effects of computer use and job tasks on the changes in the PTPP, Table 5 shows the detailed estimates of the contribution of changes in computer use and job tasks on changes in the PTPP between 1997 and 2001 (Panel A), 1997-2006 (Panel B) and 1997-2012 (Panel C). The table divides the decomposition estimates of the explained portion of the decrease in the PTPP into a quantity effect (change in importance of tasks) and a price effect (change in wage returns to tasks). Column 1 shows the overall explained contribution of computer use and job tasks in the decreased PTPP. Column 2 shows the portion of the contribution that is explained by changes in the importance of computer use and job tasks. Column 3 shows the portion that is explained by changes in the wage returns to computer use and job tasks. The table shows that 34 per cent $[(0.020 / 0.059) \times 100]$ of the explained change in the PTPP between 1997 and 2001 and 61 per cent $[(0.042 / 0.070) \times 100]$ of the explained change between 1997 and 2006 are due to changes in the importance of job tasks. Between 1997 and 2012, changes in the importance of tasks are more than fully responsible for the overall explained change in the PTPP over this period of time, because the price effect of time has increased the PTPP over this period.

The estimates presented in Column 1 show that joint changes in the quantity and prices of computer use as well as reading and writing reduced the PTPP over time, while joint changes in the quantity and prices of influencing have increased the PTPP over time. Column 2 shows that particularly the 
TABLE 5

The Contribution of Computer Use and Job Tasks in the Explained Part of the PTPP in Low and Medium-Skilled Occupations

\begin{tabular}{|c|c|c|c|}
\hline & $\begin{array}{l}(1) \\
\text { Overall } \\
\text { explained } \\
\text { changes }\end{array}$ & $\begin{array}{c}\text { (2) } \\
\text { Changes in importance } \\
\text { of tasks (Quantity } \\
\text { effects) }\end{array}$ & $\begin{array}{l}\text { (3) } \\
\text { Changes in wage } \\
\text { returns to task } \\
\text { (Price effect) }\end{array}$ \\
\hline \multicolumn{4}{|l|}{ (A) 1997-2001 } \\
\hline Computer use & -0.003 & -0.013 & 0.010 \\
\hline Physical & 0.001 & 0.006 & -0.004 \\
\hline Problem solving & -0.014 & -0.003 & -0.011 \\
\hline Self-planning & -0.013 & -0.002 & -0.011 \\
\hline Influencing & 0.014 & -0.005 & 0.019 \\
\hline External communication & 0.004 & 0.000 & 0.004 \\
\hline Literacy & -0.039 & -0.002 & -0.036 \\
\hline Maths & -0.009 & 0.000 & -0.009 \\
\hline Total & -0.059 & -0.020 & -0.039 \\
\hline \multicolumn{4}{|l|}{ (B) 1997-2006 } \\
\hline Computer use & -0.026 & -0.023 & -0.004 \\
\hline Physical & 0.002 & 0.004 & -0.002 \\
\hline Problem solving & -0.004 & -0.004 & 0.000 \\
\hline Self-planning & -0.009 & -0.008 & -0.001 \\
\hline Influencing & 0.003 & -0.006 & 0.009 \\
\hline External communication & 0.003 & 0.003 & 0.000 \\
\hline Literacy & -0.023 & -0.008 & -0.015 \\
\hline Maths & -0.015 & 0.000 & -0.014 \\
\hline Total & -0.070 & -0.042 & -0.027 \\
\hline \multicolumn{4}{|l|}{ (C) 1997-2012 } \\
\hline Computer use & -0.033 & -0.030 & -0.003 \\
\hline Physical & -0.005 & -0.005 & 0.000 \\
\hline Problem solving & -0.006 & -0.003 & -0.003 \\
\hline Self-planning & 0.016 & -0.007 & 0.023 \\
\hline Influencing & 0.017 & -0.008 & 0.025 \\
\hline External communication & -0.013 & -0.003 & -0.010 \\
\hline Literacy & -0.044 & -0.016 & -0.028 \\
\hline Maths & 0.006 & -0.001 & 0.008 \\
\hline Total & -0.061 & -0.074 & 0.012 \\
\hline
\end{tabular}

Note: Overall explained change (1) = Task changes (2) + Task price changes (3). A positive sign indicates an increase in the PTPP, and a negative sign indicates a decrease in the PTPP.

convergence in computer use between part-time and full-time workers explains a great deal of the decrease in the PTPP, while the convergence in the selfplanning, influencing and reading and writing tasks between part-time and full-time workers explain only a small portion of the decrease in the PTPP. Column 3 shows that changes in the prices of reading and writing lead to a convergence in the PTPP. However, changes in the prices of influencing led to a divergence in the PTPP. This divergence exceeded the effect of the convergence in the input of influencing tasks between part-time and full-time workers. This also holds for self-planning and maths between 1997 and 2012. ${ }^{21}$ This makes the overall impact of these tasks on the PTPP negative. 
The results from Table 5 indicate that shifts in computer use and job tasks explain a great deal of the improvement in part-time workers' pay. However, this improvement in pay is not merely due to changes in the importance of job tasks by part-time compared to full-time workers. The increase in parttime workers' relative pay could also be partly explained by changes in the wage returns to particular tasks. On one hand, as wage returns to particular tasks which are more often done by full-timers have decreased over time. These tasks became less important in explaining the PTPP than they were in the past. Consequently, even when a gap between part-timers and full-timers in the importance of these job tasks remains, the change in the returns to these job tasks can partly explain the lower PTPP. Reading and writing is a typical example of such job tasks. On the other hand, as wage returns to particular tasks which are more often done by full-timers have increased over time, these tasks became more important in explaining the PTPP than they used to be in the past. Consequently, even when the gap between part-time and fulltime workers in the importance of these job task decreases, changes in the wage returns to these job tasks can negatively affect the PTPP. This holds for influencing tasks.

\section{Conclusion}

This article documents recent changes in the PTPP for female workers in low- and medium-skilled occupations in the United Kingdom over the period 1997 to 2012; a period which witnessed substantial decline in the prices of ICT. The article investigates to what extent the change in the PTPP is driven by changes in computer use and other job tasks of full-time and part-time workers. We find that the PTPP decreased significantly between 1997 and 2012. The decrease in the PTPP has been accompanied by a convergence in computer use and influencing tasks between part-time and full-time workers. This convergence particularly took place within occupations. This suggests that the PTPP decreased due to improvements in the relative productivity of part-time workers instead of changes in the occupational segregation between part-time and full-time workers.

While the convergence in computer use explains a substantial part of the decrease in the PTPP, the decline in the PTPP has also been affected by changes in the wage returns to job tasks which are performed more intensively by full-time workers. On the one hand, the decreasing returns to reading and writing tasks have contributed to decrease the PTPP. On the other hand, the increasing returns to influencing have increased the PTPP despite the convergence in the importance of influencing between part-time and full-time workers. Altogether, relative changes in the importance of and wage returns to computer use and other job tasks explain more than 50 per cent of the wage convergence between part-time and full-time workers in low- and mediumskilled occupations. 
The article shows that a task-based approach offers a highly relevant framework to analyse changes in the labour market position of part-time workers. It also provides suggestive evidence that in recent years the positive effects of technological change, driven by the decreasing prices of IT, on labour market outcomes seems to be more pronounced for vulnerable groups of workers such as those who are employed in part-time jobs.

Final version accepted on 9 December 2015

\section{Acknowledgements}

We acknowledge the comments and suggestions of two anonymous referees, Sinem Ayhan, Arnaud Chevalier, Tommaso Colussi, Benjamin Elsner, Francis Green, Daniel Hamermesh, Annemarie Künn-Nelen, Maryam Naghsh Nejad, Milena Nikolova, Massimiliano Tani, Maria Zumbühl, the participants at the DUHR seminar meeting at Maastricht University, the annual INSCOPE Research for Innovation workshop at the University of Twente, the conference 'Cognitive and Non-Cognitive Skills over the Life Cycle' at Maastricht University, the international conference 'Inequalities, Skills and Globalization' in Lille, France and the second international BIBB/IAB workshop T.A.S.K.S. 2 in Bonn, Germany.

\section{Notes}

1. We show, however, descriptive statistics for workers in high-skilled occupations.

2. The convergence in these job tasks is in line with the findings of Gallie and Zhou (2011) who showed improvement in the educational level as well as training attainments for the UK female part-time relative to male full-time workers over the period 1992-2006.

3. Replicating the analyses without sample restrictions gives similar pattern of results.

4. The subjective measure of part-time employment is closest to the legal definition of part-time employment (Manning and Petrongolo 2008). However, we get similar results when we replicate our analysis using a commonly used measure of parttime employment based on working for less than 30 hours per week (e.g. Connolly and Gregory 2008, 2009; Mumford and Smith 2009).

5. We get similar results when we replicate the analyses using the complexity of computer use, where respondents were asked to indicate the level of their computer use on a four-point scale (using examples to explain the various levels).

6. Despite the difficulty to classify all seven categories of tasks into clear-cut routine vs. non-routine groups, Green (2012) states that it is fairly clear that some of these categories can be safely classified as 'non-routine' (e.g. influencing and selfplanning). However, it is hard to identify a priori which tasks are 'routine'. Given this difficulty, we do not emphasize the link between computerization and the different kinds of tasks. Instead, we include computer use as one of the generic tasks and study its direct impact on wages. 
7. Using the 'SOC 2000' occupational classification, we consider the occupational categories 1 'managers and senior officials' and 2 'professional occupations' to be high-skilled occupations, and all other occupations in the classification to be low- and medium-skilled. See Elias and McKnight (2001) for more details on the classification of occupations by skill.

8. The figure also shows a slight increase in the PTPP between 2006 and 2012. However, this increase is not statistically significant. The slight increase in the PTPP in 2012 might be due to the economic crisis that could have negatively affected the relative labor market position of part-time workers given that they often have less favorable labor contracts and are more often low-skilled.

9. The literature shows that physical and external communication tasks are negatively related to pay, which suggests that individuals with abundant amounts of these skills sort into low-pay occupations (e.g. Green 2012).

10. Running the same descriptive analysis for highly-skilled occupations, we find significant convergence in computer use between part-time and full-time workers. The share of part-time workers in high-skilled occupations increased slightly from $19.88 \%$ in 1997 to $22.63 \%$ in 2012 . However, this increase is statistically insignificant.

11. This means that observations from 1997 take the value 1 , observations from 2001 take the value 5 and observations from 2006 and 2012 take the values 10 and 16, respectively.

12. The non-discriminatory coefficient is calculated by weighting the least squares estimates from the individual earnings equations as follows: $\hat{\lambda}^{*}=\Omega \hat{\lambda}_{y 2}+(1-\Omega) \hat{\lambda}_{y 1}$ where $\Omega=\left(\dot{J}_{y 2} \dot{J}_{y 2}+\dot{J}_{y 1} J_{y 1}\right)^{-1}\left(\hat{J}_{y 2} J_{y 2}\right)$ is the OaxacaRansom weighting matrix.

13. This means that $\theta_{y}^{\mathrm{FT}}=e_{y}^{\mathrm{FT}} / \sigma_{y}^{\mathrm{FT}}$ where $e_{t}^{\mathrm{FT}}$ is the residual from the wage equation of full-timers in year $y$.

14. To account for the increase in the PTPP between 2006 and 2012, we re-estimated the model including a dummy variable for the wave 2006. This gives similar results. We have also replicated the analysis after dropping the wave 2006. Despite the drop in the number of observations, the estimation results are similar.

15. For an extensive discussion on the endogeneity problem of part-time employment, see Fernández-Kranz and Rodríguez-Planas (2011).

16. The descriptive statistics presented in Table A2 show that physical tasks are more important for part-time workers. However, the pattern changes after including the controls.

17. To account for the possibility that the convergence in pay, computer use and job tasks between part-time and full-time workers could be driven by relative changes in some demographic and background characteristics between part-time and full-time workers such as marital status and education (see Table A3), we re-estimated the equations (1) and (2) after controlling for the relative changes over time between part-time and full-time workers in marital status and education (i.e. by including triple interaction terms of these variables, time and part-time dummy). We get qualitatively similar results to those shown in Tables 1 and 2 . As a further robustness check, we have re-estimated equations (1) and (2) after excluding workers who are younger than 25 years old to account for the possibility that young-aged workers are more likely to combine part-time work with study and therefore, could have a different profile of tasks and pay. Estimation results are, however, robust to the omission of this group. 
18. Estimates from Column 7 are, by definition, identical to difference in difference estimates shown in Table A3.

19. For occupation cells with only few observations we merged occupations so that each occupation includes at least 50 part-time workers. We have also reestimated the analysis using three-digit occupations with at least 30 part-time observations within an occupation. Table A5 shows the estimates when we use 3-digit occupations. The table show that the part of the decrease in the PTPP that took place within occupations gets even larger with 65 per cent $[(0.043 / 0.066) \times 100]$ between 1997 and 2001,90 per cent $[(0.124 / 0.138) \times 100]$ between 1997 and 2006 and 80 per cent $[(0.091 / 0.115) \times 100]$ in the full period $1997-$ 2012.

20. To illustrate the relevance of the task-based approach in explaining the PTPP, we compare the PTPP which remains after controlling for job tasks to the PTPP that remains after accounting for occupational segregation. For this purpose, we estimate an earnings equation in which we regress log wage on a part-time dummy and insert job tasks, as an alternative to occupational dummies. As shown in Table A6, job tasks explain the PTPP almost equally well as occupational dummies do. However, as shown in Table 3, the task-based approach has the advantage over occupational dummies that it does not only capture shifts over time in the PTPP across, but also within occupations.

21. The prices of self-planning and maths show a change in sign from reducing the PTPP between 1997 and 2006 to increasing the PTPP in 2012. This suggests that the returns to these tasks have increased over time. Since full-timers have higher scores on self-planning and maths, this increase has a negative effect on the relative pay of part-time workers.

\section{References}

Acemoglu, D. (1998). 'Why do new technologies complement skills? Directed technical change and wage inequality'. Quarterly Journal of Economic, 113 (4): 1055-89.

Autor, D., Levy, F. and Murnane, R. (2003). 'The skill content of recent technological change: an empirical exploration'. Quarterly Journal of Economics, 118 (4): 1279333.

Black, S. E. and Spitz-Oener, A. (2010). 'Explaining women's success: technological change and the skill content of women's work'. Review of Economics and Statistics, 92 (1): 187-94.

Blau, F. D. and Kahn, L. M. (1992). 'The gender earnings gap: learning from international comparisons'. American Economic Review, 82 (2): 533-8.

— and (1997). 'Swimming upstream: trends in the gender wage differential in the 1980s'. Journal of Labor Economics, 15 (1): 1-42.

Booth, A. L. and van Ours, J. C. (2013). 'Part-time jobs: what women want?' Journal of Population Economics, 26 (1): 263-83.

Connolly, S. and Gregory, M. (2008). 'Moving down: women's part-time work and occupational change in Britain 1991-2001'. Economic Journal, 118 (526): F52-76.

— and _ (2009). 'The part-time pay penalty: earnings trajectories of British women’. Oxford Economic Papers, 61 (Suppl. 1): i76-97.

— and (2010). 'Dual tracks: part-time work in life-cycle employment for British women'. Journal of Population Economics, 23 (3): 907-31. 
Dickerson, A. and Green, F. (2004). 'The growth and valuation of computing and other generic skills'. Oxford Economic Papers, 56 (3): 371-406.

Elias, P. and McKnight A. (2001). 'Skill measurement in official statistics: recent developments in the UK and the rest of Europe'. Oxford Economic Papers, 53 (3): 508-40.

Ermisch, J. F. and Wright R.E. (1993). 'Wage offers and full-time and part-time employment by British women'. Journal of Human Resources, 28 (1): 111-33.

Fernández-Kranz, D. and Rodríguez-Planas, N. (2011). 'The part-time pay penalty in a segmented labor market'. Labour Economics, 18 (5): 591-606.

Gallie, D. and Zhou, Y. (2011). 'The changing job skills of female part-time workers in Britain 1992-2006'. Human Resource Management Journal, 21 (1): 28-44.

Garicano, L. and Rossi-Hansberg E. (2006). 'Organization and inequality in a knowledge economy'. Quarterly Journal of Economics, 121 (4): 1383-435.

Green, F. (2012). 'Employee involvement, technology and evolution in job skills: a task-based analysis'. Industrial and Labor Relations Review, 65 (1): 36-67.

Gupta, N. D., Oaxaca, R. L. and Smith, N. (2006). 'Swimming upstream, floating downstream: comparing women's relative wage progress in the United States and Denmark'. Industrial and Labor Relations Review, 59 (2): 243-66.

Hirsch, B. T. (2005). 'Why do part-time workers earn less? The role of worker and job skills'. Industrial and Labor Relations Review, 58 (4): 525-51.

Iseke, A. (2014). 'The part-time job satisfaction puzzle: different types of job discrepancies and the moderating effect of family importance'. British Journal of Industrial Relations, 52 (3): 445-69.

Juhn, C., Murphy, K. M. and Pierce, B. (1991). 'Accounting for the slowdown in black-white wage convergence'. In M. H. Kosters (ed.), Workers and Their Wages. Washington, DC: AEI Press, pp. 107-43.

Lindley, J. (2012). 'The gender dimension of technical change and the role of task inputs'. Labour Economics, 19 (4): 516-26.

Manning, A. and Petrongolo, B. (2008). 'The part-time pay penalty for women in Britain'. Economic Journal, 118 (526): F28-51.

Mumford, K. and Smith, P. N. (2009). 'What determines the part-time and gender earnings gaps in Britain: evidence from the workplace'. Oxford Economic Papers, 61 (Suppl. 1): i56-75.

Oaxaca, R. L. and Ransom, M. R. (1994). 'On discrimination and the decomposition of wage differentials'. Journal of Econometrics, 61 (1): 5-21.

Snower, D. and Goerlich, D. (2013). 'Multitasking and wages'. IZA Working paper No. 7426, Bonn.

Spitz-Oener, A. (2006). 'Technical change, job tasks, and rising educational demands: looking outside the wage structure'. Journal of Labor Economics, 24 (2): 235-70. 


\section{Appendix}

TABLE A1

The List of the Job Tasks in the UK Skills Survey (Green 2012)

\footnotetext{
Reading and writing

Reading written information, e.g. forms, notices or signs

Reading short documents, e.g. Letters or memos

Reading long documents, e.g. Long reports, manuals, etc.

Writing material such as forms, notices or signs

Writing short documents, e.g. Letters or memos

Writing long documents with correct spelling/grammar

Maths

Adding, subtracting, multiplying or dividing numbers

Calculations using decimals, percentages or fractions

More advanced mathematical or statistical procedures.

External communication

Knowledge of particular products or services

Selling a product or service

Counselling, advising or caring for customers or clients.

Dealing with people
}

Influencing

Instructing, training or teaching people

Persuading or influencing others.

Making speeches or presentations

Planning the activities of others

Listening carefully to colleagues

Self-planning

Planning your own activities

Organizing your own time

Thinking ahead

Problem solving

Spotting problems or faults

Working out the cause of problems or faults

Thinking of solutions to problems

Analysing complex problems in depth

Physical tasks

Physical strength, e.g. carry, push or pull heavy objects

Work for long periods on physical activities

Skill or accuracy in using your hands or fingers

Use or operate tools, equipment or machinery 
TABLE A2

Differences in Pay, Job Tasks and Background Characteristics between PT and FT Workers

\begin{tabular}{|c|c|c|c|c|c|c|}
\hline \multirow[t]{2}{*}{ Variable } & \multicolumn{3}{|c|}{$\begin{array}{l}\text { Low and medium-skilled } \\
\text { occupations }\end{array}$} & \multicolumn{3}{|c|}{ High-skilled occupations } \\
\hline & FT & PT & FT-PT & FT & PT & FT-PT \\
\hline Log wage & 1.98 & 1.81 & $0.17^{* * *}$ & 2.37 & 2.50 & $-0.13^{* *}$ \\
\hline Computer use & 0.84 & 0.67 & $0.17^{* * *}$ & 0.98 & 0.95 & $0.03^{* *}$ \\
\hline Physical & 1.85 & 1.92 & $-0.07^{* *}$ & 1.41 & 1.39 & 0.02 \\
\hline Problem solving & 2.74 & 2.30 & $0.44^{* * *}$ & 3.15 & 2.92 & $0.23^{* * *}$ \\
\hline Self-planning & 3.02 & 2.52 & $0.50^{* * *}$ & 3.63 & 3.45 & $0.18^{* * *}$ \\
\hline Influencing & 2.18 & 1.79 & $0.39^{* * *}$ & 3.01 & 2.82 & $0.19^{* * *}$ \\
\hline External comm. & 2.68 & 2.56 & $0.12^{* * *}$ & 2.92 & 2.69 & $0.23^{* * *}$ \\
\hline Read and write & 2.56 & 2.00 & $0.56^{* * *}$ & 3.14 & 2.95 & $0.19^{* * *}$ \\
\hline Maths & 1.73 & 1.28 & $0.45^{* * *}$ & 2.27 & 1.97 & $0.30^{* * *}$ \\
\hline Age & 39.43 & 41.08 & $-1.65^{* * *}$ & 40.43 & 42.98 & $-2.55^{* * *}$ \\
\hline Married & 0.42 & 0.60 & $-0.18^{* * *}$ & 0.48 & 0.72 & $-0.24^{* * *}$ \\
\hline Have children & 0.29 & 0.59 & $-0.30^{* * *}$ & 0.30 & 0.63 & $-0.33^{* * *}$ \\
\hline No qualification & 0.11 & 0.19 & $-0.08^{* * *}$ & 0.02 & 0.02 & 0.00 \\
\hline Qualification level 1 & 0.08 & 0.12 & $-0.04^{* * *}$ & 0.03 & 0.02 & 0.01 \\
\hline Qualification level 2 & 0.29 & 0.31 & $-0.02^{* *}$ & 0.10 & 0.09 & 0.01 \\
\hline Qualification level 3 & 0.21 & 0.20 & $0.01^{*}$ & 0.16 & 0.11 & $0.05^{*}$ \\
\hline Qualification level 4 & 0.30 & 0.18 & $0.12^{* * *}$ & 0.69 & 0.75 & $-0.06^{* *}$ \\
\hline Work experience & 18.69 & 18.69 & 0.00 & 18.36 & 18.70 & -0.34 \\
\hline Trained & 0.60 & 0.45 & $0.15^{* * *}$ & 0.77 & 0.79 & -0.02 \\
\hline Private sector & 0.39 & 0.39 & 0.00 & 0.51 & 0.67 & $-0.16^{* * *}$ \\
\hline Firm size $<25$ & 0.31 & 0.50 & -0.19 & 0.28 & 0.38 & -0.10 \\
\hline Firm size 25-99 & 0.28 & 0.24 & 0.04 & 0.35 & 0.31 & 0.04 \\
\hline Firm size $100-499$ & 0.23 & 0.16 & 0.07 & 0.22 & 0.16 & 0.06 \\
\hline Firm size $>500$ & 0.17 & 0.10 & 0.07 & 0.16 & 0.14 & 0.02 \\
\hline Observations & 3106 & 2483 & & 1167 & 315 & \\
\hline
\end{tabular}

Note: Qualification level 1 corresponds to GCSE grade D or lower (national exams normally taken at age 16). Qualification level 2 refers to GCSE grade A-C or vocational equivalent. Qualification level 3 denotes A-level qualifications or their vocational equivalents. Qualification level 4 refers to tertiary diplomas, bachelor's degrees and above.

${ }^{* * *} p<0.01,{ }^{* *} p<0.05,{ }^{*} p<0.1$. 


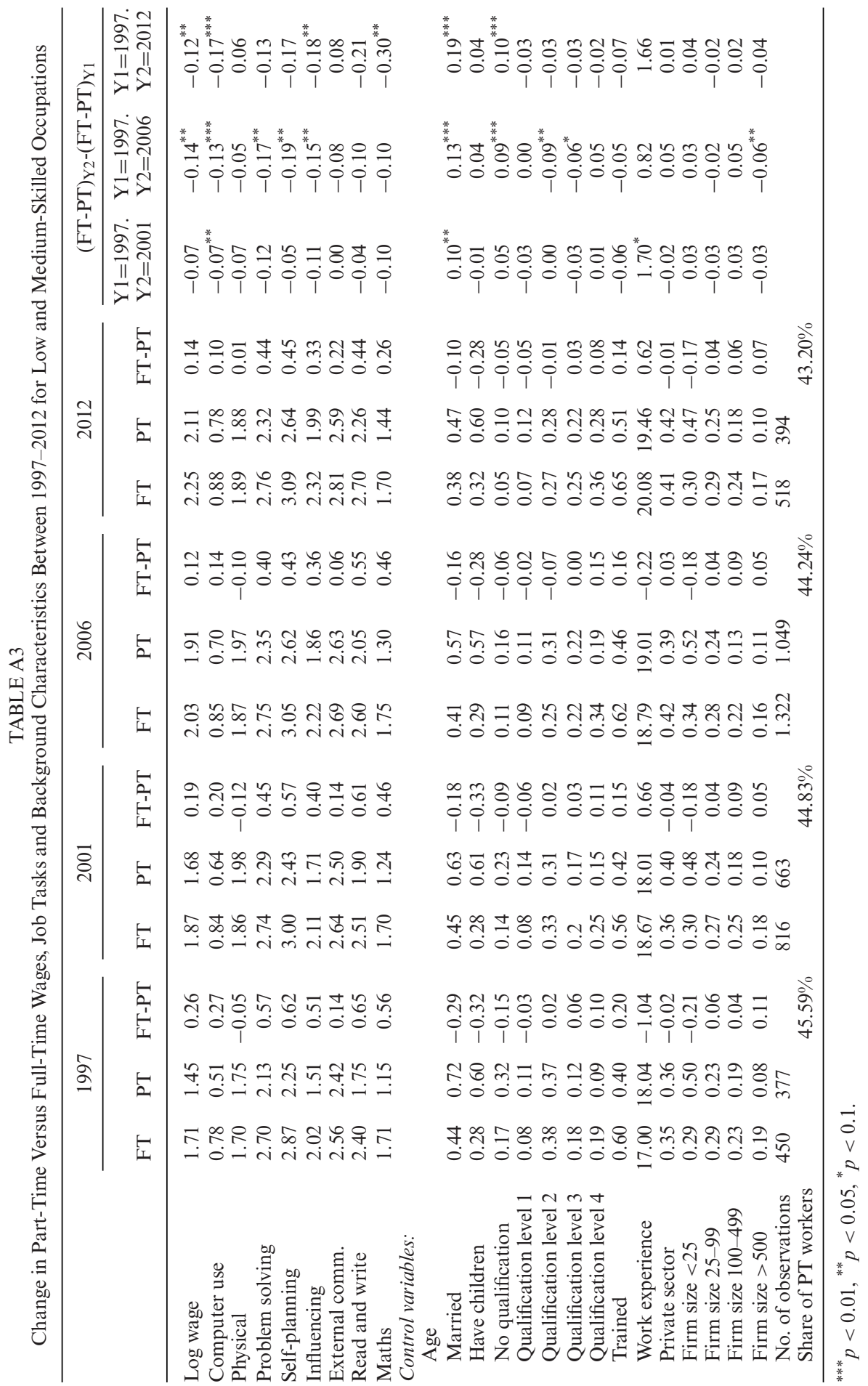

C 2016 John Wiley \& Sons Ltd/London School of Economics. 
TABLE A4

Heckman Selection Procedure to Estimate Changes in the PTPP Over the Period 1997-2012

\begin{tabular}{|c|c|c|}
\hline Variables & $\begin{array}{c}(1) \\
\text { Log wage }\end{array}$ & $\begin{array}{c}(2) \\
\text { Log wage }\end{array}$ \\
\hline Part-timer & $\begin{array}{c}-0.146^{* * *} \\
(0.049)\end{array}$ & $\begin{array}{c}-0.076 \\
(0.057)\end{array}$ \\
\hline Year & $\begin{array}{l}0.035^{* * *} \\
(0.002)\end{array}$ & $\begin{array}{l}0.031^{* * *} \\
(0.002)\end{array}$ \\
\hline Part-timer*Year & $\begin{array}{l}0.009^{* *} \\
(0.004)\end{array}$ & $\begin{array}{l}0.007^{* *} \\
(0.003)\end{array}$ \\
\hline $\begin{array}{l}\text { Occupational dummies } \\
\text { Controls }\end{array}$ & $\begin{array}{l}\text { No } \\
\text { No }\end{array}$ & $\begin{array}{l}\text { Yes } \\
\text { Yes }\end{array}$ \\
\hline Constant & $\begin{array}{l}1.644^{* * *} \\
(0.028)\end{array}$ & $\begin{array}{l}1.736^{* * * *} \\
(0.141)\end{array}$ \\
\hline Lambda & $\begin{array}{c}-0.062^{* *} \\
(0.024)\end{array}$ & $\begin{array}{c}-0.012 \\
(0.032)\end{array}$ \\
\hline Observations & 5589 & 5589 \\
\hline
\end{tabular}

TABLE A5

Oaxaca-Ransom Decomposition of the Change in the PTPP, Computer Use and Job Tasks Over the Period 1997-2012 Using 3-Digit Occupations

\begin{tabular}{|c|c|c|c|c|c|c|c|}
\hline & (1) & (2) & (3) & (4) & (5) & (6) & (7) \\
\hline & \multicolumn{3}{|c|}{ Within occupations } & \multicolumn{3}{|c|}{ Across occupations } & Overall Change \\
\hline & FT & PT & $\begin{array}{c}\text { FT-PT } \\
(1)-(2)\end{array}$ & FT & PT & $\begin{array}{l}\text { FT-PT } \\
(4)-(5)\end{array}$ & $(3)+(6)$ \\
\hline \multicolumn{8}{|l|}{ A) $1997-2001$} \\
\hline Pay & 0.127 & 0.170 & -0.043 & 0.030 & 0.053 & -0.023 & -0.066 \\
\hline Computer use & 0.038 & 0.069 & -0.031 & 0.022 & 0.064 & -0.042 & -0.073 \\
\hline Physical & 0.218 & 0.250 & -0.032 & $-0.056-$ & -0.017 & -0.039 & -0.071 \\
\hline Problem solving & 0.009 & 0.071 & -0.062 & 0.036 & 0.091 & -0.055 & -0.117 \\
\hline Self-planning & 0.058 & 0.100 & -0.042 & 0.068 & 0.079 & -0.011 & -0.053 \\
\hline Influencing & -0.002 & 0.100 & -0.102 & 0.091 & 0.097 & -0.006 & -0.108 \\
\hline External communication & 0.004 & 0.023 & -0.019 & 0.081 & 0.061 & 0.020 & 0.001 \\
\hline Literacy & 0.041 & 0.003 & 0.038 & 0.072 & 0.140 & -0.068 & -0.030 \\
\hline Maths & -0.115 & -0.039 & -0.076 & 0.106 & 0.126 & -0.020 & -0.096 \\
\hline \multicolumn{8}{|l|}{ B) 1997-2006 } \\
\hline Pay & 0.290 & 0.414 & -0.124 & 0.024 & 0.038 & -0.014 & -0.138 \\
\hline Computer use & 0.066 & 0.147 & -0.081 & 0.001 & 0.049 & -0.048 & -0.129 \\
\hline Physical & 0.123 & 0.225 & -0.102 & 0.049 & -0.001 & 0.050 & -0.052 \\
\hline Problem solving & 0.002 & 0.125 & -0.123 & 0.053 & 0.100 & -0.047 & -0.170 \\
\hline Self-planning & 0.110 & 0.243 & -0.133 & 0.070 & 0.122 & -0.052 & -0.185 \\
\hline Influencing & 0.083 & 0.227 & -0.144 & 0.117 & 0.120 & -0.003 & -0.147 \\
\hline External communication & 0.045 & 0.164 & -0.119 & 0.087 & 0.049 & 0.038 & -0.081 \\
\hline Literacy & 0.125 & 0.169 & -0.044 & 0.073 & 0.130 & -0.057 & -0.101 \\
\hline Maths & -0.017 & 0.012 & -0.029 & 0.059 & 0.141 & -0.082 & -0.111 \\
\hline
\end{tabular}


TABLE A5

Continued

\begin{tabular}{|c|c|c|c|c|c|c|c|}
\hline & (1) & (2) & (3) & (4) & (5) & (6) & (7) \\
\hline & \multicolumn{3}{|c|}{ Within occupations } & \multicolumn{3}{|c|}{ Across occupations } & Overall Change \\
\hline & FT & PT & $\begin{array}{l}\text { FT-PT } \\
(1)-(2)\end{array}$ & FT & PT & $\begin{array}{c}\text { FT-PT } \\
(4)-(5)\end{array}$ & $(3)+(6)$ \\
\hline \multicolumn{8}{|l|}{ C) 1997-2012 } \\
\hline Pay & 0.508 & 0.599 & -0.091 & 0.032 & 0.056 & -0.024 & -0.115 \\
\hline Computer use & 0.112 & 0.210 & -0.098 & -0.008 & 0.062 & -0.070 & -0.168 \\
\hline Physical & 0.115 & 0.156 & -0.041 & 0.081 & -0.024 & 0.105 & 0.064 \\
\hline Problem solving & 0.010 & 0.055 & -0.045 & 0.049 & 0.136 & -0.087 & -0.132 \\
\hline Self-planning & 0.143 & 0.232 & -0.089 & 0.081 & 0.157 & -0.076 & -0.165 \\
\hline Influencing & 0.136 & 0.301 & -0.165 & 0.162 & 0.180 & -0.018 & -0.183 \\
\hline External communication & 0.115 & 0.128 & -0.013 & 0.142 & 0.045 & 0.097 & 0.084 \\
\hline Literacy & 0.187 & 0.312 & -0.125 & 0.117 & 0.191 & -0.074 & -0.199 \\
\hline Maths & -0.046 & 0.150 & -0.196 & 0.034 & 0.136 & -0.102 & -0.298 \\
\hline
\end{tabular}

Note: A negative sign means a decrease in the PTPP. In terms of equation (3): (1) $=\left[J_{y 2}\left(\hat{\lambda}_{y 2}-\right.\right.$ $\left.\left.\hat{\lambda}^{*}\right)+\left(J_{y 1}\right)\left(\hat{\lambda}^{*}-\hat{\lambda}_{y 1}\right)\right]_{\mathrm{FT}},(2)=\left[J_{y 2}\left(\hat{\lambda}_{y 1}-\hat{\lambda}^{*}\right)+\left(J_{y 1}\right)\left(\hat{\lambda}^{*}-\hat{\lambda}_{y 1}\right)\right]_{\mathrm{PT}},(3)=(1)-(2),(4)=\left[\left(J_{y 2}-\right.\right.$ $\left.\left.J_{y 1}\right) \hat{\lambda}^{*}\right]_{\mathrm{FT}},(5)=\left[\left(J_{y 2}-J_{y 1}\right) \hat{\lambda}^{*}\right]_{\mathrm{PT}},(6)=(4)-(5)$ and $(7)=(3)+(6)$.

TABLE A6

OLS Estimates for the PTPP

Variables

Log wage

(1) (2)

(3)

Part-timer

$-0.169^{* * *}$
$(0.017)$

$-0.050^{* * *}$
$(0.017)$

$-0.049 * * *$

Computer use

Physical tasks

Problem solving

$-0.048^{* * *}$

Self-planning

$(0.008)$

0.003

$(0.011)$

Influencing

$(0.010)$

External comm.

$0.090^{* * *}$

$(0.013)$

Read and write

$-0.049^{* * *}$

$(0.010)$

Maths

$0.052^{* * *}$

$(0.011)$

$-0.007$

Occupational dummies

Controls

Constant

No
No
$1.980^{* * *}$
$(0.012)$
5589
0.017

$(0.008)$

Observations

$R^{2}$

0.017

Yes
No
$2.370^{* * *}$
$(0.024)$
5589
0.134

No

No

$1.555^{* * *}$

$(0.035)$

5589

0.105

Note: OLS estimations, standard errors in parentheses ${ }^{* * *} p<0.01,{ }^{* *} p<0.05,{ }^{*} p<0.1$. 